\title{
Sudden Death Due to Thrombosis Associated with Implantable Cardioverter-Defibrillator Electrodes
}

\author{
Jose Maria Frutos Perez ${ }^{1}$, Marina Llopis Sanchis ${ }^{1}$, Beatriz Moreno Torres², Andrea Esteve Villar del Saz ${ }^{3}$, \\ Ana Ventura Esteve ${ }^{1}$, Maria Angeles Martinez Pascuall ${ }^{1}$, Mariam Perea Ribis ${ }^{1}$, Alba Camarena Molina ${ }^{1}$, Leyre Jorquer Vidal ${ }^{1}$, \\ Gustavo Lobato Correia ${ }^{1}$, Jose Manuel Querol Ribelles ${ }^{1}$ \\ ${ }^{1}$ Department of Internal Medicine, Section of Internal Medicine, Hospital Francesc de Borja, Gandia, Valencia, Spain \\ ${ }^{2}$ Department of Anatomic Pathology, Hospital Francesc de Borja, Gandia, Valencia, Spain \\ ${ }^{3}$ Department of Internal Medicine, Section of Pneumology, Hospital Francesc de Borja, Gandia, Valencia, Spain
}

\section{Doi: 10.12890/2021_002247 - European Journal of Case Reports in Internal Medicine - ๑ EFIM 2021}

Received: 02/01/2021

Accepted: 31/01/2021

Published: 08/03/2021

\begin{abstract}
How to cite this article: Frutos Perez JM, Llopis Sanchis M, Moreno Torres B, Esteve Villar del Saz A, Ventura Esteve A, Martinez Pascual MA, Perea Ribis M, Camarena Molina A, Jorquer Vidal L, Lobato Correia G, Querol Ribelles JM. Sudden death due to thrombosis associated with implantable cardioverterdefibrillator electrodes. EJCRIM 2021;8: doi:10.12890/2021_002247.
\end{abstract}

Conflicts of Interests: The Authors declare that there are no competing interests.

This article is licensed under a Commons Attribution Non-Commercial 4.0 License

\section{ABSTRACT}

Thrombosis associated with pacemaker leads is extremely rare, although the literature on this subject is scarce. A clinical case is reported, describing this condition and its clinical presentation, the complementary tests for establishing the diagnosis and the available therapeutic options.

\section{LEARNING POINTS}

- Thrombosis associated with pacemaker leads is extremely rare.

- The different causes that contribute to thrombosis all have Virchow's triad (blood stasis, endothelial injury/dysfunction and hypercoagulability) in common.

- Transthoracic and/or transoesophageal Doppler echocardiography is the gold standard for establishing the diagnosis, while the treatment options are anticoagulation, thrombolysis and surgical or endovascular embolectomy.

\section{KEYWORDS}

Implantable cardioverter-defibrillator, thrombosis, sudden death

\section{CASE DESCRIPTION}

A 70-year-old woman presented with a history of arterial hypertension, hypothyroidism, bilateral massive pulmonary thromboembolism 12 years previously, non-ischaemic dilated cardiomyopathy, moderate mitral valve insufficiency and a left ventricular ejection fraction of 29\%. She carried an implantable automatic defibrillator-cardiac resynchronization therapy (IAD-CRT) device in the context of primary prevention. The patient was receiving chronic treatment with apixaban, spironolactone, sacubitril/valsartan, levothyroxine and megestrol. The patient was admitted to Internal Medicine from the emergency room with suspected decompensated heart failure and respiratory infection. She reported progressive dyspnoea to the point where breathing became laboured in response to minimum physical exertion, with no clear orthopnoea, scantly productive cough and a worsened general condition. Dysphonia, dysphagia, hyporexia and disorientation in time and space were noted. Empirical treatment had been started from primary care with levofloxacin due to suspected respiratory 
infection. Treatment was subsequently changed to cefuroxime due to limited improvement of the respiratory symptoms and the persistence of dyspnoea.

The chest x-rays showed increased density with a nodular appearance in the middle lobe, without changes versus previous radiographic studies; a differential diagnosis between round pneumonia and right lung mass was considered. Laboratory tests revealed scant elevation of acute phase reactants, with D-dimer elevation to $2,150 \mathrm{ng} / \mathrm{ml}$. Polymerase chain reaction testing for SARS-CoV-2 proved negative upon admission and again 3 days later.

Following admission, empirical antibiotic therapy was started with intravenous ceftriaxone $2 \mathrm{~g} / 24 \mathrm{~h}$ and oral azithromycin $500 \mathrm{mg} / 24 \mathrm{~h}$. The patient's regular treatment was maintained, with the exception of apixaban, which was replaced by full-dose bemiparin.

The clinical course evolved slowly during admission, with persistence of the disorientation and dyspnoea, despite improvement in the laboratory test parameters. Vascular computed tomography of the pulmonary arteries was decided upon to discard new pulmonary thromboembolism and/or lung neoplastic disease. While this study was pending, the patient died suddenly.

Following death, the IAD evidenced no arrhythmias explaining the fatal outcome. The relatives were therefore asked to authorize a postmortem study (clinical autopsy).

The autopsy revealed the presence of an intracavitary thrombus measuring $5 \times 2.5 \mathrm{~cm}$ in size and occupying the right atrioventricular valve, encompassing and adhering to the IAD electrodes (Fig. 1).

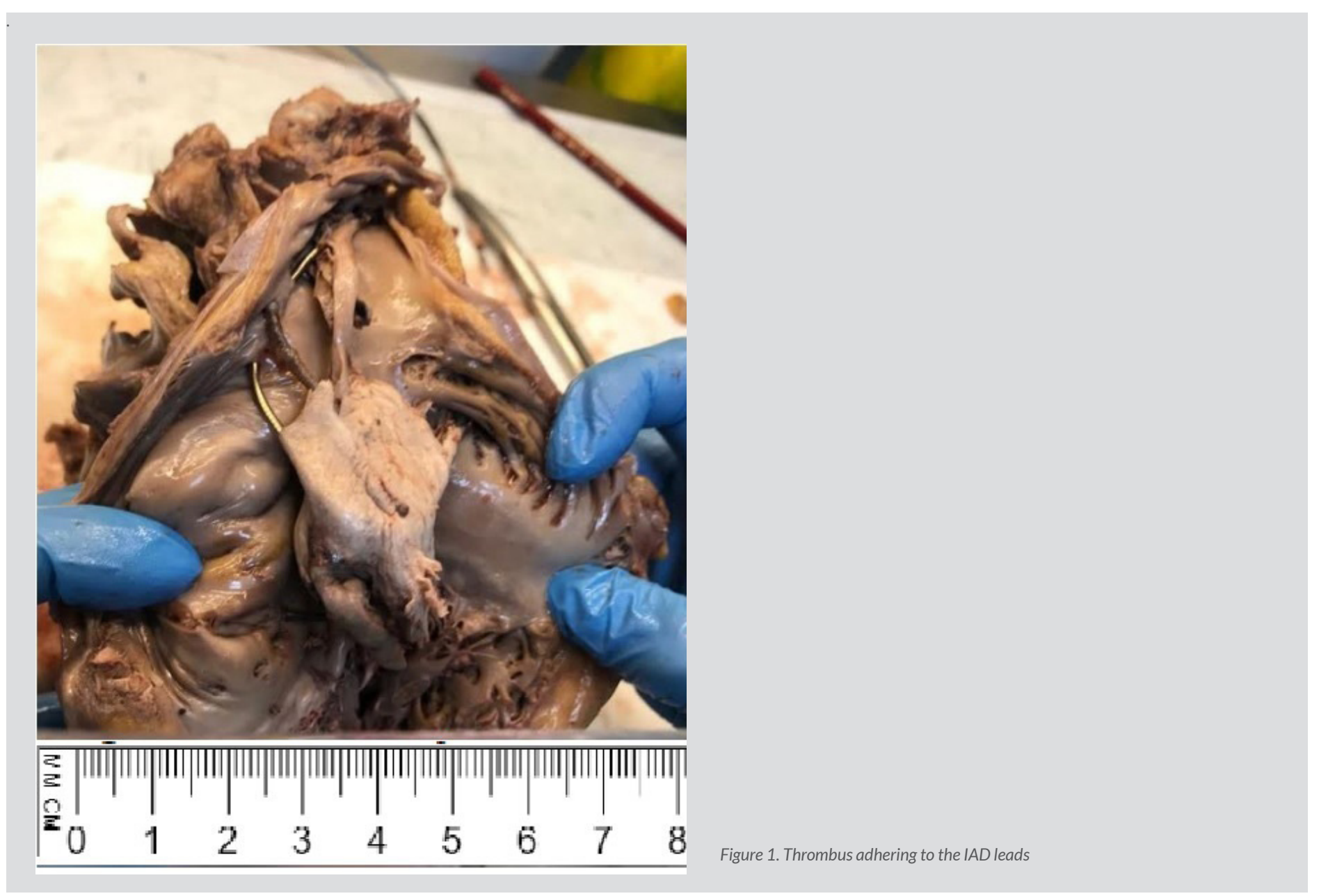

In addition, a previously unknown tumour mass measuring $4 \times 3 \mathrm{~cm}$ in size was identified in the right upper lung lobe, compressing the right main bronchus and pulmonary vessels. Large cell neuroendocrine carcinoma was diagnosed, with different lymph node, liver and bone metastases.

Following the study, the cause of death was considered to be the large thrombosis associated with the IAD leads. In turn, the metastatic neuroendocrine carcinoma and the rest of the disease antecedents contributed to the prothrombotic state of the patient. 


\section{DISCUSSION}

Intracardiac masses can be classified into 3 types: thrombi, tumours and vegetations. Thrombi are the most common presentation ${ }^{[1]}$, with atrial fibrillation being their most frequent predisposing factor. Other conditions contributing to thrombosis are valve disease, left atrial appendage stasis, the presence of intracardiac devices, a worsened ventricular ejection fraction, dilated cardiomyopathy, ischaemic heart disease or ventricular aneurysm ${ }^{[2]}$. A common element in all these disorders is the so-called Virchow's triad (blood stasis, endothelial injury/ dysfunction and hypercoagulability) ${ }^{[3-5]}$.

Venous thrombosis following pacemaker implantation is frequent, with a reported annual incidence of $23 \%{ }^{[6]}$. Right-side intracavitary thrombi often originate from the peripheral venous circulation ( $3.8 \%$ in patients with deep venous thrombosis), although they may also arise in situ ${ }^{[3,5,7-9]}$. However, the identification of an intracardiac thrombus related to a permanent pacemaker electrode is extremely rare ${ }^{[3]}$. A recent autopsy-based study reported an incidence of right atrial thrombi associated with permanent pacemaker leads of $14 \%{ }^{[5]}$.

Transthoracic and/or transoesophageal colour Doppler echocardiography is the gold standard for the diagnosis of intracardiac masses. However, imaging techniques such as computed tomography or magnetic resonance imaging are preferred for distinguishing between intracavitary thrombi and tumours, with a view to assessing vascularization of the mass ${ }^{[10]}$. Intracavitary thrombus embolization risk factors are mobility, intracavitary protrusion, the presence of a pedicle and an origin in akinetic or hyperkinetic zones of the cardiac wall ${ }^{[1]}$.

The treatment options comprise anticoagulation, thrombolysis and surgical or endovascular embolectomy. However, anticoagulation has not been shown to significantly reduce the size of the thrombus, and thrombolysis in turn may fragment the thrombus, giving rise to pulmonary embolism ${ }^{[11]}$.

\section{REFERENCES}

1. Medrano-Plana Y, Mirabal-Rodríguez R, Chao-García JL, Bermúdez-Yera R, Nápoles-Lizano ME, Aparicio-Suárez JL. Trombo gigante en aurícula derecha como causa de angina y sincope. Cor Salud 2012;4:216-220.

2. Marques JS, Gato VM, Ferreira R, Nobre A, Almeida A, De Sousa J. Intracardiac sterile pacemaker lead thrombosis. Rev Esp Cardiol 2012;65:193-194.

3. Egolum U, Stover D, Anthony R, Wasserman A, Lenihan D, Damp J. Intracardiac thrombus: diagnosis, complications and management. Am J Med Sci 2013;345:391-395.

4. García-Fernández R, Valiente-Mustelier J, Cabrera-Rego JO, Díaz-Padrón R. Trombo en tránsito en aurícula derecha. Rev Fed Arg Cardiol 2010;39(1):58-60.

5. Novak M, Dvorak P, Kamaryt P, Slana B, Lipoldova J. Autopsy and clinical context in deceased patients with implanted pacemakers and defibrillators: intracardiac findings near their leads and electrodes. Europace 2009;11:1510-1516.

6. Van Rooden CJ, Molhoek SG, Rosendaal FR, Schalij MJ, Meinders AE, Huisman MV. Incidence and risk factors of early venous thrombosis associated with permanent pacemaker leads. J Cardiovasc Electrophysiol 2004;15:1258-1262.

7. Marques JS, Gato VM, Ferreira R, Nobre A, Almeida A, De Sousa J. Intracardiac sterile pacemaker lead thrombosis. Rev Esp Cardiol 2012;65:193-194.

8. García-Fernández R, Valiente-Mustelier J, Cabrera-Rego JO, Díaz-Padrón R. Trombo en tránsito en aurícula derecha. Rev Fed Arg Cardiol 2010;39(1):58-60.

9. Waller BF, Grider L, Rohr TM, McLaughlin T, Taliercio CP, Fetters J. Intracardiac thrombi: frequency, location, etiology, and complications: a morphologic review. Clin Cardiol 1995;18:477-479.

10. Delange-Segura L. Limitaciones de la ecocardiografía transesofágica en la valoración de masas intracardiacas. A propósito de un caso. Rev Esp Anestesiol Reanim 2005;52:421424.

11. Chrzanowski L, Fiutowski M, Krzeminska-Pakula M, Wierzbowska-Drabik K, Drozdz J, Wozniakowski B, et al. Images in cardiovascular medicine. The meta-morphosis of the thrombus after thrombolytic therapy. Circulation 2007;115:e646-e647. 